\title{
Case Files of the Harvard Medical Toxicology Fellowship at Children's Hospital Boston: An Insulin Overdose
}

\author{
Aaron Benjamin Skolnik • Michele Burns Ewald
}

Published online: 20 August 2010

(C) American College of Medical Toxicology 2010

Keywords Insulin · Insulin pump · Overdose ·

Hypoglycemia $\cdot$ Diabetes $\cdot$ Adolescent

\section{Case Presentation}

A 16-year-old boy with a history of type I diabetes mellitus being managed with an insulin pump presented to the emergency department in cardiac arrest. Per report from the patient's mother, the patient had noticed that his insulin cartridge, containing insulin lispro, was empty the night prior to admission so he had replaced it at approximately 7:00 PM. He had used his glucometer through the night with recorded values of $225-389 \mathrm{mg} / \mathrm{dL}$ and had administered a total of 14.5 units of insulin via his pump. At around 6:30 AM, the morning of admission, his mother attempted to wake him for school and found him cyanotic and motionless. She attempted to obtain a fingerstick glucose measurement but was unable to do so and administered glucagon, as well as activating Emergency Medical Services (EMS). When EMS arrived, the patient was pulseless. Cardiopulmonary resuscitation was initiated, and the patient was endotracheally intubated. Point-of-care

A. B. Skolnik · M. B. Ewald

Harvard Affiliated Emergency Medicine Residency,

Brigham and Women's/Massachusetts General Hospital (AS); Division of Emergency Medicine, Harvard Medical Toxicology Fellowship, Children's Hospital Boston (MBE),

Boston, MA, USA

\section{A. B. Skolnik $(\square)$}

Harvard Affiliated Emergency Medicine Residency,

75 Francis Street, Neville House 236A,

Boston, MA 02115, USA

e-mail: askolnik@partners.org glucose determination was $81 \mathrm{mg} / \mathrm{dL}$. He received epinephrine, atropine, naloxone, and an ampule of $50 \%$ dextrose (25 g) during his prehospital care. He was defibrillated twice at $200 \mathrm{~J}$ for ventricular fibrillation. He was transferred to the emergency department with cardiopulmonary resuscitation in progress. EMS reported that an empty insulin syringe had been seen underneath the patient's bed. After approximately $1 \mathrm{~h}$ of resuscitative efforts, during which the patient received additional epinephrine, sodium bicarbonate, and hydrocortisone, he had return of spontaneous circulation. His initial arterial blood gas revealed a $\mathrm{pH}$ of $6.8, \mathrm{PaCO}_{2}$ of $70 \mathrm{mmHg}$, and $\mathrm{PaO}_{2}$ of $335 \mathrm{mmHg}$. His serum glucose at that time was $377 \mathrm{mg} / \mathrm{dL}$, and the anion gap was $39 \mathrm{mEq} / \mathrm{L}$ with urine negative for ketones. He underwent computed tomography scan of the head, chest, abdomen, and pelvis that demonstrated left upper lobe consolidation and gastric distention but was otherwise normal. He was transferred to a tertiary-care children's hospital where his serum glucose on arrival was $50 \mathrm{mg} / \mathrm{dL}$. He received $25 \mathrm{~g}$ of intravenous dextrose, and an infusion of $10 \%$ dextrose in normal saline was started. A toxicology consult was obtained.

\section{What Types of Insulin are Routinely Available for Outpatient Therapy?}

There are 15 Food and Drug Administration-approved drug products with insulin as the active ingredient [1]. Currently available recombinant insulin products are designed to have dramatically different pharmacokinetic profiles to facilitate multiple strategies for outpatient glucose management $[2,3]$.

Currently available insulins can be divided into prandial or corrective insulin and basal insulin. Prandial insulins have a more rapid onset and shorter duration of action and 
are meant to mimic the natural rise in plasma insulin concentration after eating. These are typically given at mealtimes. Basal insulins provide longer duration of action and imitate the body's baseline insulin secretion. These products can be given without respect to meals, typically once or twice daily.

Insulins can be further divided, based on the onset and duration of their effect. Rapid-acting insulin has the fastest onset of action, shortest time to peak effect, and shortest duration of action. Short-acting insulin has a rapid onset of action, with a delayed peak and longer duration of action, lasting up to $10 \mathrm{~h}$. Intermediate-acting insulin has a peak effect at 4 to $14 \mathrm{~h}$ after administration, while long-acting insulin has no significant peak effect. The effects of both intermediate-acting and long-acting insulin may last up to $24 \mathrm{~h}$. Rapid-acting insulins are used in insulin pumps, which are discussed in greater detail below. Proprietary mixes of prandial and basal insulins are also available to minimize the number of doses that patients must administer daily for those on a regimen of multiple daily injections [3]. Available products are compared in Table 1.

\section{What are the Advantages and Risks of Insulin Pump Therapy?}

Delivery of subcutaneous insulin via external pumps, known as continuous subcutaneous insulin infusion (CSII), has existed since the late 1970s. Originally used for treating patients with labile type I diabetes, this technology has become increasingly widespread in recent years. Principally, rapid-acting insulin is infused from a cartridge or syringe encased in a pump, through a catheter, and into the body through a subcutaneous needle or cannula. Insulin is continuously infused to provide basal glucose control, and programmable boluses are given to account for the glucose load of daily meals [4]. Multiple studies of CSII have found that it improves glycemic control and reduces long-term complications of diabetes, including a growing body of experience with CSII in the pediatric population. Patients in the Diabetes Control and Complications Trial (DCCT) who were treated with CSII experienced lower rates of diabetic complications and lower glycated hemoglobin levels. CSII has also been shown to decrease fasting glucose levels and decrease glucose variability [5].

An expert panel meeting in 2009 identified six areas of potential safety problems with CSII via insulin pump: software, hardware, wireless communication, alarms, bolusdose calculation, and human factors, all of which have been documented in the medical literature [6]. Technical risks associated with CSII include impaired insulin delivery via depleted battery charge or insulin supply, detachment of the cannula or needle, leakage of insulin, and kinked infusion tubing. Insulin may precipitate and cause catheter or tubing obstruction. Failure to correctly prime the pump or tubing can lead to failure of insulin delivery [7]. Hardware and software errors including autocalculation of bolus doses that may lead to overmedication or undermedication. Human or manufacturing errors in refilling the pump or changes in dosage, concentration, or type of insulin infused are all opportunities for pump-related drug error [8, 9]. The feared "run-away pump" that delivers a large insulin overdose has been reported, but appears to be exceptionally rare [10-12]. Complete pump failure has been reported after electrostatic shock [13], and there is a single case report of a recently developed tubeless CSII system malfunctioning in a hospital work environment, presumably due to electromagnetic interference [14].

Early studies on CSII found an increased incidence of ketonemia and diabetic ketoacidosis (DKA) [15, 16], but

Table 1 Comparison of available insulin products by pharmacokinetic profile

\begin{tabular}{|c|c|c|c|c|c|c|}
\hline $\begin{array}{l}\text { Generic name (all are } \\
\text { recombinant insulin) }\end{array}$ & Proprietary name & $\begin{array}{l}\text { Concentration } \\
(\mathrm{U} / \mathrm{mL})\end{array}$ & Type & $\begin{array}{l}\text { Onset of } \\
\text { action }\end{array}$ & $\begin{array}{l}\text { Time to peak } \\
\text { effect }\end{array}$ & $\begin{array}{l}\text { Duration } \\
\text { of action }\end{array}$ \\
\hline Aspart & Novolog & 100 & Rapid-acting & $10-30 \mathrm{~min}$ & $1-3 \mathrm{~h}$ & $3-5 \mathrm{~h}$ \\
\hline Glulisine & Apidra & 100 & Rapid-acting & $10-30 \mathrm{~min}$ & $40-120 \mathrm{~min}$ & $3-4 \mathrm{~h}$ \\
\hline Lispro & Humalog & 100 & Rapid-acting & $15-30 \mathrm{~min}$ & $30-90 \mathrm{~min}$ & $3-5 \mathrm{~h}$ \\
\hline Human & Humulin R & 100 or 500 & Short-acting & $30-60 \mathrm{~min}$ & $2.5-5 \mathrm{~h}$ & $3-8 \mathrm{~h}$ \\
\hline NPH Human & Humulin N, Novolin N & 100 & Intermediate-acting & $1-2 \mathrm{~h}$ & $6-10 \mathrm{~h}$ & $14-24 \mathrm{~h}$ \\
\hline Detemir & Levemir & 100 & Long-acting & $3-4 \mathrm{~h}$ & $6-8 \mathrm{~h}$ & $6-24 \mathrm{~h}$ \\
\hline Glargine & Lantus & 100 & Long-acting & $3-4 \mathrm{~h}$ & No peak & $10.8-24 \mathrm{~h}$ \\
\hline Aspart Protamine; Aspart & Novolog mix $70 / 30$ & 70:30 Mix & Intermediate + Rapid-acting & $\sim 10-30 \mathrm{~min}$ & $\sim 1-3 \mathrm{~h}$ & $\mathrm{Up}$ to $24 \mathrm{~h}$ \\
\hline Lispro Protamine; Lispro & Humalog mix 50/50 & 50:50 Mix & Intermediate + Rapid-acting & $\sim 15-30 \mathrm{~min}$ & $\sim 30 \min -5.5 \mathrm{~h}$ & $10-20 \mathrm{~h}$ \\
\hline Lispro Protamine; Lispro & Humalog mix $75 / 25$ & $75: 25$ Mix & Intermediate + Rapid-acting & $\sim 15-30 \quad \mathrm{~min}$ & $1-6.5 \mathrm{~h}$ & $\mathrm{Up}$ to $24 \mathrm{~h}$ \\
\hline
\end{tabular}

Adapted from references [2], [65], and [66] 
this has not been substantiated in subsequent research. There was also the suggestion of increased mortality among users of CSII, but this was later refuted [10]. In the DCCT trial, patients in the intensive glucose control group had a higher incidence of severe hypoglycemic episodes among both adult and adolescent patients [17, 18]. Among adolescent study subjects, there was a nearly threefold higher incidence of hypoglycemia requiring treatment assistance (85.7 vs. 27.8 episodes per 100 patient-years) in the intensively treated group. Those episodes included 26.7 episodes of seizure or coma per 100 patient-years in the intensive glucose control group and 9.7 such episodes in the conventional treatment group. Among intensive treatment group subjects, 14 were hospitalized for treatment of hypoglycemia, compared with 5 hospitalizations in those conventionally managed [17]. However, although the DCCT trial was not designed to compare incidence of hypoglycemia in CSII versus multiple daily injections, it has been reported that there was no greater incidence of hypoglycemia in the subgroup of patients that received CSII [19]. Two additional studies showed no greater increase in hypoglycemia with use of CSII versus conventional insulin therapy, and subsequent data suggested that severe hypoglycemic episodes might actually be reduced by CSII when compared with multiple daily insulin injections $[15,20]$. A recent meta-analysis done of 15 randomized trials of CSII versus multiple daily injections found no significant difference in severe or nocturnal hypoglycemia between the two therapies [21]. In a newly published multicenter randomized controlled trial of glucose sensoraugmented CSII therapy versus a regimen of multiple daily insulin injections, CSII produced a significantly lower glycated hemoglobin level at 1 year, with no significant difference in the rate of severe hypoglycemia between the two groups [22].

The Food and Drug Administration has studied medical device adverse event reports for insulin pumps in adolescents over a 10 -year period, revealing 13 deaths. Reported deaths were related to either hyperglycemic or hypoglycemic complications $(n=5)$, DKA $(n=3)$, seizure $(n=1)$, or coma $(n=1)$; three death reports did not indicate a cause. There were multiple additional reports related to nonfatal hypoglycemic events that "appeared to be device-related" and two reports of attempted suicide via intentional bolus of insulin through the pump [9]. There are also at least three reports in the literature of factitious nonfatal hypoglycemia in pediatric patients using CSII, where the function normally used to prime the pump tubing was used to bolus insulin and thereby escape recording by the bolus memory feature [23, 24]. Finally, in an unusual isolated case report, an insulin pump has been successfully used as a murder weapon to deliver a lethal dose of etomidate and atracurium [25].

\section{Case Continuation}

The patient was admitted, still unresponsive, to the pediatric intensive care unit (ICU). Additional history was obtained from the patient's parents. Two weeks prior to his cardiac arrest, the patient had a hypoglycemic episode secondary to an overly generous bolus administered after having eaten pizza. At that time, glucagon was administered at home, and the patient did not seek medical attention. He and his family contacted his diabetes nurse who recommended that he continue his current CSII regimen, with special attention to avoiding large boluses for eating at night. According to the patient's diabetes nurse educator, there had been recent concerns about a flat affect and possible depression, but attempts to connect the patient to counseling were not successful.

In the ICU, the endocrinology service was consulted and the patient was maintained on continuous insulin infusion titrated to his serum glucose, with the aim of preventing ketoacidosis. In the first $72 \mathrm{~h}$ of his hospitalization, the patient had fevers to a maximum temperature of $39.1^{\circ} \mathrm{C}$ and was empirically treated with vancomycin and ceftriaxone for possible left upper lobe pneumonia. His ICU course was further complicated by episodes of tonic eye deviation, rhythmic head-bobbing, and hypertension. These were felt to be consistent with seizures and abated with lorazepam. He was given a loading dose and then maintenance therapy with fosphenytoin for these events. As of hospital day 3, the patient had reactive pupils and some spontaneous swallowing and gagging movements, but other brainstem reflexes were absent. Neurology consultation was obtained, and magnetic resonance imaging of the brain was performed to further clarify the extent of brain injury and the patient's prognosis.

\section{What Diagnostic Testing is Useful in a Known or Suspected Insulin Overdose?}

Serial measurement of plasma glucose either by bedside or laboratory determination is the critical for a patient who may have received an overdose of insulin. It is generally believed that diabetic patients who are accustomed to supranormal blood glucose levels may experience symptoms of hypoglycemia due to rapid decline in plasma glucose levels, even if an individual measurement is within the normal laboratory range. If the history obtained is not consistent with insulin or antidiabetic agent overdose, a directed medical evaluation for other causes of hypoglycemia should be pursued.

In case of suspected insulin overdose, two additional laboratory tests may be useful to the treating clinician: insulin level and C-peptide. A basic understanding of the 
chemistry of insulin secretion is important to appreciating the utility of the C-peptide. Insulin is initially synthesized as preproinsulin in the pancreatic $\beta$-islet cells. This single chain of amino acids is cleaved to form proinsulin. Proinsulin then spontaneously folds to form a doublestranded molecule with two chains of amino acids connected by disulfide bonds. Once packaged into secretory granules, the folded portion of the molecule is enzymatically cleaved off, leaving a double-stranded insulin molecule and the connecting segment remnant known as the C-peptide. Under normal conditions, insulin and C-peptide are always released in equimolar amounts into the circulation. C-peptide has no known biologic activity of its own $[26,27]$.

In a nondiabetic patient, insulin secretion should be suppressed in the presence of hypoglycemia, and both insulin and C-peptide levels should be low. If hypoglycemia is secondary to endogenous secretion of insulin or to insulin secretagogues, such as sulfonylureas, serum insulin concentrations are elevated, as are C-peptide concentrations. If exogenous insulin has been administered, insulin concentrations will be high and C-peptide concentrations will be low. Our hospital's laboratory reference range for insulin levels is 2-18 $\mu \mathrm{U} / \mathrm{mL}$, with the normal range of C-peptide levels 0.8 $3.5 \mathrm{ng} / \mathrm{mL}$ [28]. Note, however, that specific insulin levels do not correlate well with the degree of hypoglycemia.

The molar ratio of insulin to C-peptide can be determined to further assist in differentiating endogenous versus exogenous insulin. In order to make such a calculation, one needs to know that the molecular weight of insulin is $\sim 5,800 \mathrm{Da}$ and the molecular weight of C-peptide is $3,021 \mathrm{Da}$. Conveniently, $1 \mu \mathrm{U}$ is equal to $1 \mathrm{ng}$ of insulin. To calculate the number of nanomoles of each substance, divide the level expressed in nanograms per milliliter by the molecular weight in Daltons. Then, divide the number of nanomoles of insulin by the number of nanomoles of Cpeptide to obtain the molar ratio. As the half-life of Cpeptide is longer than that of insulin, the molar ratio of insulin to C-peptide will always be less than 1, unless exogenous administration of insulin has occurred [29, 30].

\section{What Adverse Events are Associated with Insulin Overdose?}

Insulin lowers serum glucose by facilitating glucose uptake by skeletal muscle, cardiac muscle, and the liver. This occurs via a membrane protein known glucose transporter 4 (GLUT4). Further, insulin inhibits hepatic gluconeogenesis and glycogenolysis. The major complications of insulin overdose all stem from the resultant hypoglycemia. This may initially result in symptomatic hypoglycemia with sweating, tachycardia, anxiety, hunger, impaired cognition, diaphoresis, and peripheral vasoconstriction [31-34]. These symptoms are caused by secretion of counterregulatory hormones, including glucagon, cortisol, epinephrine, growth hormone, norepinephrine, somatostatin, and thyroid hormones in response to low serum glucose. Autonomic dysfunction in diabetics may prevent the typical physiologic response to hypoglycemia described above $[35,36]$.

Adrenergic stimulus from counterregulatory hormone release is also thought to be responsible for the electrocardiographic abnormalities and tachydysrhythmias described in hypoglycemia. Electrocardiographic changes that may be seen include T-wave flattening and increases in the QTc interval. Patients may present with atrial fibrillation, atrial flutter, supraventricular tachycardia, ventricular tachycardia, and ventricular fibrillation [37-40]. Sudden death in known diabetic patients is often thought to be associated with hypoglycemia. In one 23-year-old diabetic man being managed with CSII who was found dead in bed having last been seen $20 \mathrm{~h}$ prior, hypoglycemia at the time of death was retrospectively confirmed by a continuous glucose monitoring system [41]. Hypoglycemia may also produce concomitant hypothermia or, rarely, hyperthermia [42]. Pulmonary edema has been reported in insulin overdose, and metabolic derangements associated with insulininduced hypoglycemia include hypokalemia, hypomagnesemia, and hypophosphatemia [43, 44].

Neurologic manifestations of low glucose are widely varied and include cognitive difficulties, change in personality and affect, dysarthria, delirium, ataxia, blurred vision, fatigue, weakness, and headache. Protracted neuroglycopenia results in agitation, seizure, coma, and eventually permanent neurologic damage and death. Focal neurologic findings of all kinds may be seen in hypoglycemic patients, but brainstem reflexes are typically preserved [26, 27, 45].

It is worth noting that allergic and hypersensitivity reactions to all types of insulin have also been reported, with an apparent declining incidence since the advent of recombinant insulin to replace animal-derived products. Although most patients undergoing insulin therapy for diabetes produce insulin-specific IgE, few have allergic complications. Neutral Protamine Hagedorn (NPH) insulin has been frequently implicated in the literature as sensitizing patients to protamine sulfate, commonly used in vascular and cardiac surgery. Severe allergic reactions including anaphylaxis and death have been reported following administration of protamine to patients previously exposed to NPH [46-54].

\section{How Should an Insulin Overdose be Managed?}

The aim of management in insulin overdose is intensive control of plasma glucose to prevent neuroglycopenia. Patients utilizing CSII should have their insulin pumps turned off and removed immediately. Frequent glucose 
determinations must be obtained, and continuous infusion of concentrated dextrose should be provided to those with symptomatic hypoglycemia or in whom a reliable exam is not obtainable. A typical starting infusion rate would be $10 \%$ or $20 \%$ dextrose at $100-200 \mathrm{~mL} / \mathrm{h}$ in an average adult, titrated to euglycemia. A sliding scale of bolus dextrose may also be required for recurrent hypoglycemia. Patients who have type I diabetes will eventually require administration of exogenous insulin to prevent ketoacidosis, as did the patient described in this case report. In patients with type II diabetes and/or residual pancreatic function, glucose must be administered with attention to the possibility of endogenous insulin release in response to rapid elevation in plasma glucose concentrations $[55,56]$.

There have been only a few case reports in the literature of early surgical excision of the injection site(s) in insulin overdose [57-59]. In one case, surgical treatment decreased the insulin elimination half-life relative to that predicted without excision [57]. However, all patients still required hospital admission and continuous dextrose infusion despite undergoing a procedure with potential to cause additional morbidity. Surgical excision cannot be recommended routinely as a treatment modality for insulin overdose.

Complications of insulin overdose should be managed supportively. Patients incapable of protecting and maintaining a patent airway should undergo endotracheal intubation and mechanical ventilation. Hypotension may respond to infusion of dextrose, although hemodynamic support with direct-acting vasopressors (e.g., norepinephrine, epinephrine) could be necessary. Hypothermia should be corrected with external warming devices, and hyperthermic patients should be cooled to normothermia. Seizures due to hypoglycemia alone should be treated with dextrose, but if the patient has suffered additional brain injury due to prolonged neuroglycopenia, anticonvulsive agents may be required. Prompt endocrinology consultation should be obtained, ideally while the patient is still in the emergency department, to assist in optimal management of the patient's glucose and prevent iatrogenic complications, such as diabetic ketoacidosis [26, 27, 45, 60-63].

\section{Case Conclusion}

The patient continued to be managed with neuroprotective measures. Blood and urine cultures had no growth. Toxicologic screening tests, including ethanol, salicylate, and cocaine testing, were negative. Echocardiography revealed no cardiac structural abnormality. The magnetic resonance imaging of the brain performed on hospital day 2 showed extensive areas of hypoxic-ischemic injury including the cerebral hemispheres, deep gray matter structures, and brainstem.
Unfortunately, the patient's poor neurologic examination never changed during his time in the ICU. Given the extent of the patient's ischemic brain injury and his grim prognosis, meetings were held between the multidisciplinary care team and the patient's family. The decision was made by the family to withdraw life-sustaining treatments on hospital day 6 . The patient died approximately $10 \mathrm{~h}$ later, having received comfort care measures after his extubation.

Endocrinology interrogation of the patient's insulin pump never revealed evidence of insulin use beyond that recorded in the pump's dose history. An insulin level drawn at the time of the patient's presentation to the emergency department returned late in the patient's hospital course and was markedly elevated at $135 \mu \mathrm{U} / \mathrm{mL}$ (normal range $=2$ $18 \mu \mathrm{U} / \mathrm{mL}$ ). A C-peptide level from blood drawn on hospital day 2 was less than $0.1 \mathrm{ng} / \mathrm{mL}(0.8-3.5 \mathrm{ng} / \mathrm{mL})$, consistent with the patient's history of type I diabetes.

The most likely explanation for the patient's cardiac arrest remains insulin overdose, perhaps via self-administration of exogenous insulin in addition to his pump, although the syringe reportedly seen by EMS at the patient's home was never located. The parents expressed regret that they had not turned off and removed their son's insulin pump upon initially finding him on the morning of his cardiac arrest. A simple way to turn off an insulin pump is by removal of the pump's battery. For those unfamiliar with a specific pump, the safest thing to do is to remove the pump, tubing, and cannula from the patient completely. The patient's family declined the option of having an autopsy performed.

Insulin overdose, whether inadvertent or intentional, presents a potentially fatal danger to patients and a challenge to clinicians. Patients living with insulin-dependent diabetes remain at high risk until new methods of glucose control are developed. Future possibilities for research include developing continuous glucose monitoring and CSII systems into an implantable artificial pancreas capable of safely autoregulating plasma glucose [64].

\section{References}

1. Active Ingredient Search (2010) In: Approved drug products with therapeutic equivalence evaluations (Orange Book). http://www. accessdata.fda.gov/scripts/cder/ob/docs/tempai.cfm. Accessed 12 Jun 2010

2. DeWitt DE, Hirsch IB (2003) Outpatient insulin therapy in type 1 and type 2 diabetes mellitus: scientific review. JAMA 289:2254 2264

3. DeWitt DE, Dugdale DC (2003) Using new insulin strategies in the outpatient treatment of diabetes: clinical applications. JAMA 289:2265-2269

4. Saudek CD (1997) Novel forms of insulin delivery. Endocrinol Metab Clin North Am 26:599-610

5. Lenhard MJ, Reeves GD (2001) Continuous subcutaneous insulin infusion: a comprehensive review of insulin pump therapy. Arch Intern Med 161:2293-2300 
6. Klonoff DC, Reyes JS (2009) Insulin pump safety meeting: summary report. J Diabetes Sci Technol 3:396-402

7. Rule AM, Drincic A, Galt KA (2007) New technology, new errors: how to prime an upgrade of an insulin infusion pump. Jt Comm J Qual Patient Saf 33:155-162

8. Guilhem I, Balkau B, Lecordier F, Malecot JM, Elbadii S, Leguerrier AM et al (2009) Insulin pump failures are still frequent: a prospective study over 6 years from 2001 to 2007 . Diabetologia 52:2662-2664

9. Cope JU, Morrison AE, Samuels-Reid J (2008) Adolescent use of insulin and patient-controlled analgesia pump technology: a 10year food and drug administration retrospective study of adverse events. Pediatrics 121:1133-1138

10. Teutsch SM, Herman WH, Dwyer DM, Lane JM (1984) Mortality among diabetic patients using continuous subcutaneous insulininfusion pumps. N Engl J Med 310:361-368

11. Wredling R, Lin PE, Adamson U (1989) Pump "run-away" causing severe hypoglycaemia. Lancet 2:273

12. Midthjell K, Kapelrud H, Bjornerud A, Claudi T, Bjorgaas M, Jervell J (1994) Severe or life-threatening hypoglycemia in insulin pump treatment. Diab Care 17:1235-1236

13. Tritos NA, Casper K, King G (1997) Museum visit leading to insulin pump malfunction. Ann Intern Med 126:746

14. Reiher AE, Gallagher TA, Emanuele MA (2009) Interference at work: a case report of a malfunctioning insulin pump. Endocr $35: 22-24$

15. Mecklenburg RS, Benson EA, Benson JW Jr, Fredlund PN, Guinn T, Metz RJ et al (1984) Acute complications associated with insulin infusion pump therapy. Report of experience with 161 patients. JAMA 252:3265-3269

16. Mecklenburg RS, Guinn TS, Sannar CA, Blumenstein BA (1986) Malfunction of continuous subcutaneous insulin infusion systems: a 1-year prospective study of 127 patients. Diab Care 9:351-355

17. Diabetes Control and Complications Trial Research Group (1994) Effect of intensive diabetes treatment on the development and progression of long-term complications in adolescents with insulin-dependent diabetes mellitus: diabetes control and complications trial. J Pediatr 125:177-188

18. The Diabetes Control and Complications Trial Research Group (1993) The effect of intensive treatment of diabetes on the development and progression of long-term complications in insulin-dependent diabetes mellitus. N Engl J Med 329:977-986

19. Kaufman FR, Halvorson M, Miller D, Mackenzie M, Fisher LK, Pitukcheewanont P (1999) Insulin pump therapy in type 1 pediatric patients: now and into the year 2000. Diabetes Metab Res Rev 15:338-352

20. Bode BW, Steed RD, Davidson PC (1996) Reduction in severe hypoglycemia with long-term continuous subcutaneous insulin infusion in type I diabetes. Diab Care 19:324-327

21. Fatourechi MM, Kudva YC, Murad MH, Elamin MB, Tabini CC, Montori VM (2009) Clinical review: hypoglycemia with intensive insulin therapy: a systematic review and meta-analyses of randomized trials of continuous subcutaneous insulin infusion versus multiple daily injections. J Clin Endocrinol Metab 94:729740

22. Bergenstal RM, Tamborlane WV, Ahmann A, Buse JB, Dailey G, Davis SN et al (2010) Effectiveness of sensor-augmented insulinpump therapy in type 1 diabetes. N Engl J Med 363:311-320

23. Osipoff JN, Sattar N, Garcia M, Wilson TA (2010) Prime-time hypoglycemia: factitious hypoglycemia during insulin-pump therapy. Pediatrics 125:1246-1248

24. Franklin VL, Bluff S, Ramsay V, Sturrock C, Greene SA, Alexander V (2007) Unexplained hypoglycaemia on a pump. Pediatr Diabetes 8:391-392

25. Benedict B, Keyes R, Sauls FC (2004) The insulin pump as murder weapon: a case report. Am J Forensic Med Pathol 25:159-160
26. Burns MJ, Levine MD (2007) Diabetic control agents. In: Shannon MW, Borron SW, Burns MJ (eds) Haddad and Winchester's clinical management of poisoning and drug overdose, 4th edn. Saunders Elsevier, Philadelphia, pp 1019-1032

27. Linden $\mathrm{CH}$ (2005) Antidiabetic agents. In: Brent J, Wallace KL, Burkhart KK, Phillips SD, Donovan JW (eds) Critical care toxicology: diagnosis and treatment of the critically poisoned patient, 1st edn. Elsevier Mosby, Philadelphia, pp 729-740

28. BWH Laboratory Handbook (2009) In: Brigham and Women's Hospital. http://www.brighamandwomens.org/clinicallabs/Medical/ lab.manual.07092009.pdf. Accessed 6 Jul 2010

29. Lebowitz MR, Blumenthal SA (1993) The molar ratio of insulin to C-peptide. An aid to the diagnosis of hypoglycemia due to surreptitious (or inadvertent) insulin administration. Arch Intern Med 153:650-655

30. Iwase H, Kobayashi M, Nakajima M, Takatori T (2001) The ratio of insulin to C-peptide can be used to make a forensic diagnosis of exogenous insulin overdosage. Forensic Sci Int 115:123-127

31. Spiller HA (1998) Management of antidiabetic medications in overdose. Drug Saf 19:411-424

32. Seltzer HS (1989) Drug-induced hypoglycemia. A review of 1418 cases. Endocrinol Metab Clin North Am 18:163-183

33. Chan JC, Cockram CS, Critchley JA (1996) Drug-induced disorders of glucose metabolism. Mechanisms and management. Drug Saf 15:135-157

34. Marks V, Teale JD (1999) Drug-induced hypoglycemia. Endocrinol Metab Clin North Am 28:555-577

35. Cryer PE (2005) Mechanisms of hypoglycemia-associated autonomic failure and its component syndromes in diabetes. Diabetes 54:3592-3601

36. Cryer PE (2004) Diverse causes of hypoglycemia-associated autonomic failure in diabetes. N Engl J Med 350:2272-2279

37. Odeh M, Oliven A, Bassan H (1990) Transient atrial fibrillation precipitated by hypoglycemia. Ann Emerg Med 19:565-567

38. Chelliah YR (2000) Ventricular arrhythmias associated with hypoglycaemia. Anaesth Intensive Care 28:698-700

39. Marques JL, George E, Peacey SR, Harris ND, Macdonald IA, Cochrane $T$ et al (1997) Altered ventricular repolarization during hypoglycaemia in patients with diabetes. Diabet Med 14:648-654

40. Lindstrom T, Jorfeldt L, Tegler L, Arnqvist HJ (1992) Hypoglycaemia and cardiac arrhythmias in patients with type 2 diabetes mellitus. Diabet Med 9:536-541

41. Tanenberg RJ, Newton CA, Drake AJ (2010) Confirmation of hypoglycemia in the "dead-in-bed" syndrome, as captured by a retrospective continuous glucose monitoring system. Endocr Pract $16: 244-248$

42. Passias TC, Meneilly GS, Mekjavic IB (1996) Effect of hypoglycemia on thermoregulatory responses. J Appl Physiol 80:1021-1032

43. Uchida D, Ohigashi S, Hikita S, Kitamura N, Motoyoshi M, Tatsuno I (2004) Acute pulmonary edema caused by hypoglycemia due to insulin overdose. Intern Med 43:1056-1059

44. Matsumura M, Nakashima A, Tofuku Y (2000) Electrolyte disorders following massive insulin overdose in a patient with type 2 diabetes. Intern Med 39:55-57

45. Bosse GM (2006) Antidiabetics and hypoglycemics. In: Flomenbaum NE, Goldfrank LR, Hoffman RS et al (eds) Goldfrank's toxicologic emergencies, 8th edn. McGraw-Hill, New York, pp 749-760

46. Stewart WJ, McSweeney SM, Kellett MA, Faxon DP, Ryan TJ (1984) Increased risk of severe protamine reactions in NPH insulin-dependent diabetics undergoing cardiac catheterization. Circulation 70:788-792

47. Gupta SK, Veith FJ, Ascer E, Wengerter KR, Franco C, Amar D et al (1989) Anaphylactoid reactions to protamine: an often lethal complication in insulin-dependent diabetic patients undergoing vascular surgery. J Vasc Surg 9:342-350 
48. Hulshof MM, Faber WR, Kniestedt WF, Boeree MJ, Kreek P (1992) Granulomatous hypersensitivity to protamine as a complication of insulin therapy. Br J Dermatol 127:286-288

49. Dykewicz MS, Kim HW, Orfan N, Yoo TJ, Lieberman P (1994) Immunologic analysis of anaphylaxis to protamine component in neutral protamine Hagedorn human insulin. J Allergy Clin Immunol 93:117-125

50. Rasanen L, Tuomi ML, Lahtela J, Knip M (1995) Hypersensitization to protamine-containing insulin. Duodecim 111:914-918

51. Blanco C, Castillo R, Quiralte J, Delgado J, Garcia I, de Pablos P et al (1996) Anaphylaxis to subcutaneous neutral protamine Hagedorn insulin with simultaneous sensitization to protamine and insulin. Allergy 51:421-424

52. Petays T, Kiistala R, Makinen-Kiljunen S (1999) Immediate protamine sulphate allergy in an insulin-treated diabetic patient. Duodecim 115:517-520

53. Bollinger ME, Hamilton RG, Wood RA (1999) Protamine allergy as a complication of insulin hypersensitivity: a case report. J Allergy Clin Immunol 104:462-465

54. Raap U, Liekenbrocker T, Kapp A, Wedi B (2005) Delayed-type hypersensitivity to protamine as a complication of insulin therapy. Contact Dermat 53:57-58

55. Adler PM (1986) Serum glucose changes after administration of $50 \%$ dextrose solution: pre- and in-hospital calculations. Am J Emerg Med 4:504-506

56. Palatnick W, Meatherall RC, Tenenbein M (1991) Clinical spectrum of sulfonylurea overdose and experience with diazoxide therapy. Arch Intern Med 151:1859-1862
57. Campbell IW, Ratcliffe JG (1982) Suicidal insulin overdose managed by excision of insulin injection site. $\mathrm{Br}$ Med $\mathrm{J}$ 285:408-409

58. McIntyre AS, Woolf VJ, Burnham WR (1986) Local excision of subcutaneous fat in the management of insulin overdose. $\mathrm{Br} \mathrm{J}$ Surg 73:538

59. Levine DF, Bulstrode C (1982) Managing suicidal insulin overdose. Br Med J 285:974-975

60. Arem R, Zoghbi W (1985) Insulin overdose in eight patients: insulin pharmacokinetics and review of the literature. Medicine 64:323-332

61. Brvar M, Mozina M, Bunc M (2005) Prolonged hypoglycaemia after insulin lispro overdose. Eur J Emerg Med 12:234-235

62. Fromont I, Benhaim D, Ottomani A, Valero R, Molines L, Vialettes B (2007) Prolonged glucose requirements after intentional glargine and aspart overdose. Diabetes Metab 33:390-392

63. Fuller ET, Miller MA, Kaylor DW, Janke C (2009) Lantus overdose: case presentation and management options. J Emerg Med 36:26-29

64. Robotic Pancreas: One Man's Quest to Put Millions of Diabetics on Autopilot (2010) In: Wired Magazine. http://www.wired.com/ magazine/2010/04/ff_pancreas/. Accessed 1 Aug 2010

65. Insulin Comparison Chart (2007) In: University of Kentucky Chandler Medical Center. http://www.hosp.uky.edu/pharmacy/formulary/ formtools/InsulinComparisonChart.pdf. Accessed 30 May 2010

66. Insulin: Compare Common Options for Insulin Therapy (2010) In: MayoClinic.com. http://www.mayoclinic.com/health/insulin/ da00091. Accessed 12 Jun 2010 